\title{
The Inclusion of Dialects in Education: An Exploration into the Use of Afan Oromo Dialects in Primary Educational Context
}

\author{
Wondimu Tegegne \\ Wolayita Soddo University, College of Social Sciences and Humanities, Wolayita Soddo, Ethiopia
}

\section{Email address:}

Wondelove7@gmail.com

To cite this article:

Wondimu Tegegne. The Inclusion of Dialects in Education: An Exploration into the Use of Afan Oromo Dialects in Primary Educational Context. International Journal of Language and Linguistics. Vol. 3, No. 6, 2015, pp. 360-366. doi: 10.11648/j.ij11.20150306.17

\begin{abstract}
The use of language varieties for instructional purposes is one of the significant factors in education. Education is claimed to be more efficient when it is provided through the medium of students' mother tongue. This, in turn, suggests the varieties which are spoken by students should be used for education. However, it is not clear whether or not the different dialects of Afan Oromo are used in the textbooks and National Exams. Hence, the main concerns of this study were to investigate the extent to which Afan Oromo dialects are used in primary education and to describe how far the educational system is inclusive or address the diverse dialect speakers. To achieve these purposes, three school subjects (one which is taught as a subject and the other two which are taught using the language) were selected for analysis. Accordingly, the contents of the students' textbooks and National Exams of Afan Oromo and two other subjects namely, Biology and Geography were selected and analyzed. Different findings were obtained from the data analysis. Regarding the use of dialects in education, the study noted that the vocabularies of the four dialect areas were used in the textbooks and National Exams, but the share given to the dialect areas does not seem similar. The data analysis also divulged that the Eastern and the Western Dialect Areas were largely used and the Central Dialect was less used in Grade 8 textbooks and National Exams. Besides, the research depicted that the use of dialects shows similarities in the National Exams and textbooks when Afan Oromo is studied as a subject and used as a Medium of Instruction (MOI). Finally, recommendations were given based on the findings of the study.
\end{abstract}

Keywords: Afan Oromo, Dialect, Education, Language, Learning, National Exam, School, Textbook

\section{Introduction}

Naturally a single language exists in different varieties (Wolfram et al., 1999). Currently, educational issues concerning dialectal variations have received popular attention worldwide (Papapavou and Pavlos, 2007). It is argued that the varieties of a language play an important role in an academic setting. Learning is claimed to be better and more successful when it is conducted in the variety spoken by students (Cheshire, 2005). Cheshire (2007: 22) further noted, "There is a general consensus, in fact, among educationalist and sociolinguistics alike, that valuing dialect in the classroom makes real difference to educational achievement of speakers." Besides, Derebsa (2006) argued that the use of the students' variety in education enables the students to use their own potential and helps them to achieve 'deep learning.' Further, the consideration of dialects in education enhances the social, cognitive, emotional and linguistic development of learners' in and out of school. For these reasons, it is said that the varieties of a language should be recognized in schools.

In Ethiopia, TGE (1991) declared and allowed the use of MTs in different spheres of life. MOE (1994) has also stated that MTs of the various nationalities can be used as a MOI until Grade 8. It is believed that there are different dialects within the same language. However, the educational policy lacks details regarding the dialect(s) that should be used for the instructional purpose and what must be done in difficult situations, like when there are diverse dialects within the same language. In such a situation, selection of the variety that will be used for a Language of Instruction (LOI) may be difficult and controversial. In Ethiopian primary schools, it is allowed that every language has the right to be taught as a subject and used as a MOI. This does not include dialect (Gfeller, 1999). Hence, the incorporation of dialects in educational system is questionable and contentious. 
Concerning this, the following questions are raised by Gfeller(1999: 6):

Which speech variety is to be considered as language, which as dialect? Several dialects can join and have one writing system. Which is the standard variety? Who decides which variety should be accepted for teaching? Who develops and decides the written standards? Who publishes the material? Using which language [dialect]? What are the responsibilities and rights of different institutions and individuals?

Despite these concerns and questions, research is lacking in applied linguistics to identify the dialects used in the three selected textbooks and National Exams of Grade 8. Therefore, this article is intended to explore the inclusion of dialects in academic contexts and analyzes the extent to which the different dialects of Afan Oromo were incorporated in Grade 8 textbooks and National Exams.

\section{Background to Afan Oromo and Its Dialects}

Oromiya is one of the Regional States in the current Federal Government of Ethiopia that is mainly inhabited by Oromo People. Oromo People speak their own native language known as Afan Oromo. Afan Oromo, Oromo Language, is an Afro-Asiatic language, and the most widely spoken of the Cushitic family. It is one of the major indigenous African languages that is widely spoken and used in most parts of Ethiopia and some parts of the neighboring countries (Mekuria, 1994). For example, Afan Oromo is spoken by 40 percent of Ethiopian population (Kebede, 2009). In Ethiopia, Afan Oromo is spoken as a lingua franca by other people who are in contact with Oromo people. According to Mekuria (1994) and Feyisa (1996), Afan Oromo is used by different nationalities such as Harari, Sidama, Anuak, Gurage, Amhara, Koma, Kulo and Kaficho as a means of communication and trade with their neighboring Oromo people. In connection to this, Amanuel and Samuel (2012:32) stated that "It [Afan Oromo] is used as a language of inter-group communication in several parts of Ethiopia."

Besides, outside Ethiopia, Afan Oromo is spoken in Kenya, Somalia, Sudan and Tanzania (Tilahun, 1993). These make Afan Oromo one of the most widely spoken languages in Africa (Bender, 1976). Afan Oromo has an officially decided writing script known as Qubee, which is based on the Latin orthography (Girma, 2001). Afan Oromo is spoken in a vast territory of Ethiopia ranging from Tigray in the North to the Central Kenya in the South, and from Wallagga in the West to Harar in the East. In these areas, it is spoken with several dialects (Ali and Zaborski, 1990).

Afan Oromo shows variations based on the geographical areas where it is spoken. Such variations are termed as regional dialects. Different attempts have been made by scholars to classify the dialects of Afan Oromo based on the geographical background of the speakers. The most recent attempt made at classifying and mapping of Afan Oromo dialects is by Kebede (2009). He conducted a detailed study on the genetic classification of Afan Oromo dialects and concluded that there are ten genetic units in Afan Oromo. Among these, six of them are the present dialect areas (i.e., Western, Central, Eastern, Wallo, Raya-spoken in Ethiopia and Waata-spoken in Kenya) and four of them (i.e., East, South-East-North, North, North-East) are historical genetic units from which the former developed. The four dialect areas, i.e., Central, Eastern, Wallo and Western were selected as a research setting for this study.

The classifications of dialects can serve as basis of planning and implementation of Oromiya Educational Program. It is argued that dialects have various impacts in education (e.g, on the learning and performance of students). For this reason, dialects should be valued and recognized in schools. This article, therefore, would explore whether or not the dialects of Afan Oromo were included in Grade 8 students' textbooks and National Examinations.

\section{Research Methodology}

The main purpose of this study was to investigate and describe the dialectal variations of Afan Oromo in primary educational context. Specifically, the research was intended to describe the extent to which Afan Oromo dialects are used in primary education and to describe how far the educational system is address the diverse dialect speakers. To achieve these purposes, it was necessary to describe the use of Afan Oromo dialects in the textbooks and National Exams. Descriptive research design was used to conduct this study, because it enables the researcher to perform the aforementioned activities.

Describing the use of Afan Oromo dialects in the Educational Program of Oromiya, i.e., Grade 8 textbooks and National Exams, was the objective of this study. To describe the use of dialects, four chapters of Afan Oromo, two chapter of Biology and two chapters of Geography textbooks were selected and analyzed. In addition, the 2012 and 2013 question papers of Afan Oromo, Biology and Geography National Exams were taken and analyzed. From each textbook, 100 words were selected. Besides, 50 words were taken from each selected National Exams of the 2012 and 2013. Hence, 300 words were selected from the textbooks and 300 words were taken from the two National Exams.

After selecting the words and expressions from the chapters and question papers, an attempt was made to obtain roughly equivalent words in the four dialect areas. To get the equivalent words in the four dialect areas, the native speaker of each dialect area were consulted. In addition, materials written on the dialects of Afan Oromo such as Mokonnen Hunde (2002), Wiirtu Jildii-7(1995), Tamane Bitima (2006) and Stegman (2007) were referred. By doing so, lists of words with their equivalents were obtained.

To analyze the words selected from the chapters of the textbooks and Exam papers, a table consisting of six columns was created. In the first column of the table, the words and 
expressions identified from the textbooks and National Exams were listed. English meanings of the identified words and expressions were given in the second column. Then, the words and expressions equivalent to the identified in the four dialect areas were illustrated in columns 3-6.

During the analysis of the textbooks and National Exams, the words and expressions having different realization (i.e., a bit different in their spelling and pronunciation), but the same in their root were considered and countered as one(similar) word. For example, in Afan Oromo National Exam of the 2012 the word 'Waliin' (Meaning with or together with in English) is 'Woliin' in the Central Dialect, 'Wajjiin' in the Eastern Dialect, 'Waliin' in the Wallo Dialect and 'Waliin/Wajjiin' in the Western Dialect. Such words were considered as synonymous. However, the words, which were entirely different in their spelling and pronunciation, were counted as different words. For example, in Geography textbook, the word "Rawwachuu" (which means accomplish in English) is "Xuиmuru/Fixuu" in the Central Dialect, "Fixuu" in the Eastern Dialect" Rawwachuu" in the Wallo Dialect and "Fixuu" in the Western Dialect. The words used in the Central, Eastern and Western Area were different from the identified word. Such words were counted as different words.

After identifying the words and expressions which were similar and different, then the result was tallied. To tally the data, the permutation or possible arrangements and combinations of the dialect areas was identified. It appeared that the four dialect areas could have 15 possible arrangements or could appear together in 15 different arrangements. Then, a table was prepared and the words were tallied on the specific raw where they fit. Then, the identified words and expressions were compared with the words of the textbooks and National Examinations. Finally, how much words taken from each dialect areas to write grade 8 textbooks and prepare the National Exams of Oromiya Region were described. Next, the result of the textbooks and question papers analysis is illustrated.

\section{Results and Discussion}

\subsection{The Actual Use of Afan Oromo Dialects in Grade 8 Textbooks of Oromiya: Result of Textbook Analysis}

When we see the use of dialects in Grade 8 Afan Oromo textbook, out of the selected 100 words, 45 words were used in the Central and the other dialect areas, 62 words were used in the Eastern and shared by the other dialect areas, 54 were words used in the Wallo and the other dialect areas and 74 words were used in the Western and the other dialect areas (See table 2). These data disclosed that the majority of the words used in Grade 8 Afan Oromo textbook were taken from the Western Dialect. However, limited words were taken from the Central Dialect compared to the other dialect areas. Hence, it can be said that the vocabularies of the different areas were used in Afan Oromo textbook. But, the share of each dialect area appears to be not similar.
The analysis of Grade 8 Biology textbook disclosed that out of the selected 100 words, 49 words were used in the Central and the other dialect areas, 74 words were used in the Eastern and shared by the other dialect areas, 54 were words used in the Wallo and the other dialect areas and 64 words were used in the Western and the other dialect areas (See table 2). The data divulged that the majority of the words used in Grade 8 Biology textbook were taken from the Eastern Dialect. More than half of the words (50) were selected from the Western and Wallo Dialect Areas. However, less than half words were taken from the Central Dialect. It can be said that Biology textbook was written by words of the four dialect areas. But it does not seem that the share given to dialect areas was similar.

Grade 8 Geography textbook analysis revealed that out of the selected 100 words, 53 words were used in the Central and the other dialect areas, 71 words were used in the Eastern and shared by other dialect areas, 62 were words used in the Wallo and the other dialect areas and 66 words were used in the Western and the other dialect areas. The data disclosed that the majority of the words used in Grade 8 Geography textbook were taken from the Eastern Dialect. More than half words (50) were from the Central, Wallo and Western Dialect Areas. Hence, the words of the four dialect areas were used in the textbook. However, the share taken from each dialect area does not seem similar.

Regarding the use of dialects in the textbooks(See table 2), the study revealed that out of the 300 words selected from Grade 8 Afan Oromo, Biology and Geography textbooks, about 147 words were taken from the Central Dialect, about 207 words were from the Eastern Dialect, about 170 words were taken from the Wallo Dialect and about 201 words were taken from the Western Dialect. That is, about $49 \%$ of the Central Dialect, about $69 \%$ of the Eastern Dialect, about $56.6 \%$ of the Wallo Dialect, about $67 \%$ of the Western Dialect was aggregately used in Grade 8 Afan Oromo, Biology and Geography textbooks. This data disclosed that the Eastern (69\%) and Western (67\%) Dialect Areas were largely used in the textbooks. But the Central Dialect (49\%) was given less share compared to the other dialect areas. The actual use of Afan Oromo dialects in the 2012 National Exams of Grade 8 is discussed next.

\subsection{The Actual Use of Afan Oromo Dialects in Grade 8 National Exams: Analysis of the 2012 National Examination Question Papers of Oromiya Region}

The dialects used in Grade 8 Afan Oromo, Biology and Geography National Exams of the 2012 were also analyzed (See table 1). As can be seen from table 1, out of the 50 words selected from Grade 8 Afan Oromo National Exam of the 2012, 17(34\%) words were used in the Central and the other dialect areas, $28(56 \%)$ vocabularies were used in the Eastern Dialect and the other dialect areas, 21(42\%) words were used in the Wallo and the other dialect areas and $42(84 \%)$ were words used in the Western Dialect and the other dialect areas. It appeared that the great majority of the words used in Grade 8 Afan Oromo National Exam of the 
2012 were taken from the Western Dialect. But, less than half of the words were taken from the Central and Wallo Dialect Areas.

Besides, among the 50 words selected from Grade 8 Biology National Exam of the 2012, 29(58\%) were used in the Central and the other dialect areas, $31(62 \%)$ were used in the Eastern and the other dialect areas, 33(66\%) vocabularies were used in the Wallo and the other dialect areas, 43(86\%) words were used in the Western Dialect and the other dialect areas. This data disclosed that the great majority of the words used in Biology National Exam of the 2012 were taken from the Western Dialect. In addition, more than half of the words were taken from the Central, Eastern and Wallo Areas.

Concerning the use of dialects in Grade 8 Geography National Exam of the 2012, the analysis of the question paper showed that 28(56\%) words were used in the Central and the other dialect areas, 26(52\%) words were used in the Eastern and the other dialect areas, 30(60\%) were words used in the Wallo and the other dialect areas and $28(56 \%)$ words were used in the Western Dialect and the other dialect areas. Hence, almost similar numbers of words were taken from the four dialect areas to write Geography National Exam of the 2004(E.C.). This result disclosed that the share given to each dialect area was almost similar.

Generally, out of the 150 words selected from Grade 8 Afan Oromo, Biology and Geography National Exams of the 2012, 74 words were selected from the Central Dialect, 85 words were taken from the Eastern Dialect, 84 words were selected from the Wallo Dialect and 113 words were taken from the Western Dialect(See table 1). This means that, about $49.3 \%$ of the Central Dialect, about $56.6 \%$ of the Eastern Dialect, about $56 \%$ of the Wallo Dialect, about $75 \%$ of the Western Dialect was used in the three National Exams. This result showed that the Western Dialect (75\%) was largely used in Afan Oromo, Biology and Geography National Exams of the 2012. But, the Central Dialect (49.3\%) was less used in the three National Exams compared to the other dialect areas. Thus, it can be said that even though the dialect areas were used in the Exams, the share given to the dialect areas was not similar. Next, the use of Afan Oromo dialects in Grade 8 National Exams of the 2013 is illustrated.

\subsection{The Actual Use of Afan Oromo Dialects in Grade 8 National Examinations: Analysis of the 2013 of National Examination Question Papers Oromiya Region}

Grade 8 National Examinations of the three selected subjects of the 2013 were also analyzed to describe the use of Afan Oromo dialects in the Exams. The analysis disclosed that out of the selected 50 words from Grade 8 Afan Oromo National Exam of the 2013 (See table 1), $19(38 \%)$ words were used in the Central and the other dialect areas, 30(60\%) words were used in the Eastern and the other dialect areas, 34(68\%) words were used in the Wallo and the other dialect areas and 33(66\%) words were used in the Western Dialect. This data revealed that the majority of the words used in Grade 8 Afan Oromo National Exam of the 2013 were taken from the Eastern, Wallo and Western Dialect Areas. However, limited words were taken from the Central Dialect. Hence, it can be said that the words of the different dialect areas were used in Grade 8 Afan Oromo National Exam of the 2013. But, the share given to the dialect areas does seem unequal.

In Grade 8 Biology National Exam of the 2013, out of the selected 50 words, $31(62 \%)$ words were used in the Central and the other dialect areas, 31(62\%) words were used in the Eastern and the other dialect areas, 35(70\%) words were used in the Wallo and the other dialect areas and 38(76\%) words were taken from the Western Dialect (See table1). Therefore, it appeared that the majority of the words used in Grade 8 Biology National Exam of the 2013 were taken from the Western Dialect $(76 \%)$ and the share given to the dialect areas does not seems similar.

The analysis of Grade 8 Geography National Exam of the 2013(See table 1) divulged that, out of the selected 50 words, $21(42 \%)$ words were used in the Central and the other dialect areas, $35(70 \%)$ words were used in the Eastern and the other dialect areas, 34(68\%) words were used in the Wallo and the other dialect areas and 31(62\%) words were taken from the Western Dialect. The data shows that there was no difference between the Eastern, and Wallo Dialect Areas. Hence, it appeared that the majority of the words taken from these dialects areas. However, limited words were taken from the Central Dialect (42\%) compared to the other dialect areas. It can be said that the words used in Grade 8 Geography National Exam of the 2013 were taken from the four dialect areas. But, the share given to the dialect areas seems not similar.

In general, out the 150 words selected from Grade 8 Afan Oromo, Biology and Geography National Exams of the 2013, (See table 1) 71 words were taken from the Central Dialect, 96 words were selected from the Eastern Dialect, 103 words were taken from the Wallo Dialect and 102 words were selected from the Western Dialect. This means about 47.3\% of the Central Dialect, about $64 \%$ of the Eastern Dialect, about $68.6 \%$ of the Wallo Dialect, about $68 \%$ of the Western Dialect was used in the three National Exams of the 2013. This data disclosed that the Eastern, Wallo and Western Dialect Areas were largely used in the 2013 National Exams. However, the share given to the Central Dialect (47.3\%) seems limited compared to the other dialect areas.

\subsection{Comparison of the Use of Afan Oromo Dialects in the 2012 with the 2013 Grade 8 National Exams Oromiya}

The Afan Oromo dialects used in the 2012 and in the 2013 National Exams of Grade 8 was compared to assess if there is similarities and differences in the use Afan Oromo dialects. The next table presents the data obtained with this regard.

As can be seen from table 2(See Item 1), the use of Afan Oromo dialects in the 2012 and 2013 Afan Oromo National Exams of Grade 8 appeared to share similarities and differences. For example, the number of the words selected from the Central Dialect was limited in the two academic 
years. However, in the 2012 Afan Oromo National Exam, the majority of the words were taken from the Western Dialect. On the other hand, almost a similar number of words were selected from the Eastern, Wallo and Western Dialect Areas in the 2013 Afan Oromo National Exam. This could show us that the home dialects of the students were considered in the 2013 than in the 2012 Afan Oromo National Exam.

Table 1: Summary of the Use of Afan Oromo Dialects in Grade 8 National Exams of the 2012 and 2013.

\begin{tabular}{|c|c|c|c|c|c|c|}
\hline \multirow{2}{*}{ No } & \multirow{2}{*}{ Grade 8 National Exam Subjects } & \multirow{2}{*}{ Year of the Exams } & \multicolumn{4}{|c|}{ DIALECT AREAS } \\
\hline & & & Central & Eastern & Wallo & Western \\
\hline \multirow{3}{*}{1} & \multirow{3}{*}{ Afan Oromo } & 2012 & 17 & 28 & 21 & 42 \\
\hline & & 2013 & 19 & 30 & 34 & 33 \\
\hline & & Total & 36 & 58 & 55 & 75 \\
\hline \multirow{3}{*}{2} & \multirow{3}{*}{ Biology } & 2012 & 29 & 31 & 33 & 43 \\
\hline & & 2013 & 31 & 31 & 35 & 38 \\
\hline & & Total & 60 & 62 & 68 & 81 \\
\hline \multirow{3}{*}{3} & \multirow{3}{*}{ Geography } & 2012 & 28 & 26 & 30 & 28 \\
\hline & & 2013 & 21 & 35 & 34 & 31 \\
\hline & & Total & 49 & 61 & 68 & 59 \\
\hline \multirow{3}{*}{4} & \multirow{3}{*}{ Aggregate } & 2012 & 74 & 85 & 84 & 113 \\
\hline & & 2013 & 71 & 96 & 103 & 102 \\
\hline & & Total & 145 & 181 & 187 & 215 \\
\hline
\end{tabular}

Item 2 table 1 also depicted that the use of Afan Oromo dialects in the 2012 and 2013 Biology National Exams of Grade 8 was similar in the Central, Eastern, and Wallo Dialect Areas in that almost similar number of words were selected from the dialect areas in the two years. Nevertheless, in the 2012 most of the words were selected from the Western Dialect. Besides, the use of Afan Oromo dialects in Grade 8 Geography National Exam of the 2012 shows that almost similar share was given to the dialect areas. However, in the 2013 limited words were selected from the Central Dialect and similar numbers of words were selected from the Eastern, Wallo and Western Dialect Areas. This could mean that the home dialects of the students were given fair representation in the 2012 than in the 2013 Geography National Exam of Grade 8.

The data in item 4(See Table 1) disclosed that out of the 150 words selected from Grade 8 Afan Oromo, Biology and Geography National Exams of the 2012, 74 words were taken from Central Dialect, 85 words from Eastern Dialect, 84 words were selected from Wallo Dialect and 113 words from the Western Dialect. This divulged that the Western Dialect was largely used in the three National Exams of the 2012. However, limited words were selected from the Central Dialect. In addition, out of the 150 words selected from Afan Oromo, Biology and Geography National Exams of the 2013, 71 words were taken from Central Dialect, 96 words were selected from Eastern Dialect, 103 words were taken from Wallo Dialect and 102 words were selected from the Western Dialect. This revealed that the Wallo and the Western Dialect Areas were largely used and Central Dialect was less used in the 2013 National Exams.

When we compare the use dialects in the Grade 8 National Exams of 2012 and 2013, it appeared that the Central Dialect was less used in the two years National Exams. Besides, the number of words selected from the Eastern and Wallo Dialect Areas were better in the 2013 National Exams. However, the
Western Dialect was more selected in the 2013 than in the 2012 National Exams. Hence, the use of Afan Oromo Dialects shows similarities in the 2012 and in the 2013.

To describe the use of dialects in Grade 8 Afan Oromo, Biology and National Exams, the words selected in the 2012 and 2013 were added together. The addition showed that about 145 words were taken from the Central Dialect, about 181 words were from the Eastern Dialect, about 187 words were from the Wallo Dialect and about 215 words were from the Western Dialect. Hence, about $48.3 \%$ of the Central Dialect, about $60.3 \%$ of the Eastern Dialect, about $62.3 \%$ of the Wallo Dialect, about $71.6 \%$ of the Western Dialect was used in the 2004 and 2013 National Exams. This data divulged that the Western Dialect $(71.6 \%)$ was largely used and the Central Dialect (48.3\%) was less used in the three National Exams of Grade 8. Nevertheless, similar share was given to the Eastern and Wallo Dialect Areas. Besides, the use of Afan Oromo dialects in Grade 8 textbooks and National Exams was compared. The next section does this.

\subsection{Comparison on the Use of Afan Oromo Dialects in Grades Textbooks and National Examinations}

The use of Afan Oromo dialects in Grade 8 textbooks and National Exams was compared. This section presents the data obtained with this regard.

Item 1 table 2 revealed that the Western Dialect was largely used and the Central Dialect was less used in both Grade 8 Afan Oromo textbook and National Exam. However, the share given to the Eastern and Wallo Dialect Areas was almost similar in both textbook and National Exam of Afan Oromo. In addition, item 2(See Table 2) disclosed that the Central, Wallo and Western Dialect Areas were more used in Grade 8 Biology National Exams than in the Textbook. However, the Eastern Dialect was more used in Biology textbook than in the National Exam. The data also indicated that the Central Dialect was less used and the Western 
Dialect was more used in both textbook and National Exam of Biology. Besides, similar numbers of words were selected from the Central, Wallo and Western Dialect areas in both Grade 8 Geography Textbook and National Exam. However, the Eastern Dialect was more used in Geography textbook. Furthermore, the data in item 3 table 2 disclosed that the Central Dialect was less used in Geography textbook and National Exam, but similar share was given to the other dialect areas. When we see aggregated data, similar numbers of the words were selected from the Central Dialect in textbooks and National Exams of Grade 8. The Eastern Dialect was more used in the textbook and the Wallo and Western Dialect areas were more used in the National Exams.

Table 2: Summary on the Use of Afan Oromo Dialects in Grade 8 Textbooks and National Exams of Oromiya Region.

\begin{tabular}{|c|c|c|c|c|c|c|}
\hline \multirow{2}{*}{ No } & \multirow{2}{*}{ Subjects } & \multirow{2}{*}{$\begin{array}{l}\text { Area of } \\
\text { Use }\end{array}$} & \multicolumn{4}{|c|}{ DIALECT AREAS } \\
\hline & & & Central & Eastern & Wallo & Western \\
\hline \multirow{3}{*}{1} & \multirow{3}{*}{$\begin{array}{l}\text { Afan } \\
\text { Oromo }\end{array}$} & Textbook & 45 & 62 & 54 & 74 \\
\hline & & $\begin{array}{l}\text { National } \\
\text { Exam }\end{array}$ & 36 & 58 & 55 & 75 \\
\hline & & Total & 81 & 120 & 109 & 149 \\
\hline \multirow{3}{*}{2} & \multirow{3}{*}{ Biology } & Textbook & 49 & 74 & 54 & 61 \\
\hline & & $\begin{array}{l}\text { National } \\
\text { Exam }\end{array}$ & 60 & 62 & 68 & 81 \\
\hline & & Total & 109 & 136 & 122 & 142 \\
\hline \multirow{3}{*}{3} & \multirow{3}{*}{ Geography } & Textbook & 53 & 71 & 62 & 66 \\
\hline & & $\begin{array}{l}\text { National } \\
\text { Exam }\end{array}$ & 49 & 61 & 68 & 59 \\
\hline & & Total & 102 & 132 & 126 & 125 \\
\hline \multirow{3}{*}{4} & \multirow{3}{*}{ Aggregate } & Textbook & 147 & 207 & 170 & 201 \\
\hline & & $\begin{array}{l}\text { National } \\
\text { Exam }\end{array}$ & 145 & 181 & 187 & 215 \\
\hline & & Total & 292 & 388 & 357 & 416 \\
\hline
\end{tabular}

\section{Conclusion on the Actual Use of the Afan Oromo Dialects in Grade 8 Textbooks and National Exams}

From the overall data presented in this article, it can be said that the vocabularies used in Grade 8 textbooks and National Exams was taken from the four dialect areas. However, the share given to the dialect areas seems to be unfair except Geography National Exam of the 2012. For instance, the majority of the words used in Grade 8 Afan Oromo textbook were taken from the Western Dialect. However, limited words were taken from the Central Dialect compared to the other dialect areas. Besides, the majority of the words used in Biology and Geography textbook were taken from the Eastern Dialect Area. In Grade 8 Geography National Exam of the 2013 limited words were taken the Central Dialect. These findings revealed that the share given to the dialect areas was not similar.

Besides, it was noted that out of the 600 words selected from Grade 8 Afan Oromo, Biology and Geography textbooks and National Exams, 292 words were taken from the Central Dialect, 388 words were from the Eastern Dialect, 357 words were from the Wallo Dialect and 416 words were selected from the Western Dialect. That is, about $48.6 \%$ of the Central Dialect, about $64.6 \%$ of the Eastern Dialect, about $59.5 \%$ of the Wallo Dialect, about $69.3 \%$ of the Western Dialect was used in the three textbooks and National Exams. These data divulged that the Eastern and the Western Dialect Areas were largely used and the Central Dialect was less used in Grade 8 textbooks and National Exams.

From the analyses of Grade 8 textbooks and National Exam papers, it can be said that words of the different dialect areas were used. However, it was noted that the share given to the dialect areas was not similar. The data also depicted that the use of dialects shows similarity in the National Exams and textbooks when Afan Oromo is studied as a subject and used as a MOI. Thus, it can be said that there are attempts to address dialects in the educational systems. This in turn, may mean that the textbooks and National Exams are contributing to development and standardization of Afan Oromo. But to standardize and develop the language, various works has to be done. Some the activities are recommended in the next section.

\section{Recommendations}

A. The dialects of Afan Oromo should be fairly represented in the textbooks and National Exams There should be fair representation of Afan Oromo dialects while preparing textbooks, National Exams and other reference materials. In addition, textbook and Exam writers should look for words almost having similar realization in the four dialect areas. They should also put optional word in a bracket if they think that the word can be difficult for students. Furthermore, the textbook and Exam writers should provide glossary at the end of the textbook where list of words with their equivalent words in different dialects is given.

B. Experts from different dialect areas should be involved in the preparation of the textbooks and National Exams. In Oromiya, students go to primary schools from different dialectal backgrounds. At schools, all students in Oromiya Region and Oromiya Zone of the Amhara Region use the same textbook and sit for the same National Exams regardless of their home dialects. In the preparation of the textbooks, writers tend to use their own dialects, which may not accommodate the other dialects (Adugna, 2009). Hence, to make students equally beneficiaries of the educational system, experts from the different dialect areas of Afan Oromo should be involved in the preparation of the textbooks and National Exams.

C. Training should be given to the textbook and National Exam writers generally on the role and contributions of dialects for the learning and achievement of students and how to select dialects for instructional purpose in multidialectal society. Specifically, the textbook and National Exam writers should be given detail training on the dialects of Afan Oromo and how they should 
select the Afan Oromo dialects for textbooks and National Exams. By doing so, it is possible to raise the awareness of the writes on the selection of dialects for textbooks and National Exams writing.

D. It is also important to provide training and orientation for teachers in the areas of language and language diversity in general, and Afan Oromo and dialects of Afan Oromo in particular. Besides, they should learn the linguistic features of Afan Oromo dialects and how to address Afan Oromo dialectal variation in the teaching learning process.

E. Afan Oromo dialects study should be given a separate section in Afan Oromo textbook. It is noted that having the awareness of the dialects of a language is important in facilitating the achievement and learning of students and in developing their language as well. Hence, dialect study should be given a separate section in Afan Oromo textbook and it should be part of language study. Particularly, students should learn dialects and their equivalent words in different areas as a lesson in Afan Oromo. Besides, variations in dialects should be encouraged in schools to show the richness of the language.

F. Mass media should play their own role in harmonizing the dialects of Afan Oromo. They can, for instance, present the meaning of words in different dialect areas. By doing so, the mass media can familiarize the varieties of Afan Oromo to the speakers of the language.

\section{References}

[1] Adugna Barkessa (2009). Terminology related problem in teaching Afan Oromo at tertiary level. (Unpublished Master's Thesis). Addis Ababa University: Ethiopia.

[2] Ali, M. and Zaborski, A. (1990). Handbook of the Oromo Language. Wroclaw: Maria Kowalska Stanis.

[3] Amanuel Raga and Samuel Adola (2012) "Homonymy as a barrier to mutual intelligibility among speakers of various dialects of Afan Oromo" on Journal of Language and Culture: Vol. 3(2), pp. 32-43.

[4] Bender, M.L. (1976). The non-Semetic languages of Ethiopia. Michigan State University: African Studies Center.

[5] Bender, M.L., Mulugeta, E. and Stinson, D. L. (1976). Two Cushitic Languages. In Bender, M.L., Bowen, J. D, Cooper, R. L. and Ferguson, C. A.(Eds). Languages in Ethiopia. London: Oxford University Press.
[6] Cheshire, J.(2005). Sociolinguistics and mother tongue education. In Ammon, U., Dittmar, N. and Trudgill, P. (Eds). (2005). Sociolinguistics: An introductory handbook of the science of language and society $\left(2^{\text {nd }}\right)$ (2341-2350). Berlin: Moutonde Gruyter.

[7] Cheshire, J. (2007). Dialect and education: Responses from sociolinguistics. In Papapavou, A. and Pavlos, P. (Eds). (2007). Sociolinguistics and pedagogical dimensions of dialect in education (14-33). Newcastle: Cambridge Scholars Publishing.

[8] Derebssa Dhufera (2006). Issues in the implementation of Ethiopian school curriculum. Robe: MadaWalabu University.

[9] Feyisa Demie (1996). Historical challenges in the development of the Oromo Language and some agenda for future research. Journal of Oromo Studies, 3(1 and 2), 18-27.

[10] Gfeller, E. (1999). Language equality: Multilingual issues in Education. Hawassa: Ethiopia.

[11] Girma Mammo. (2001). Language standardization significance: With particular reference to Afan Oromo. Wiirtuu Jildii 9, 187-216.

[12] Kebede Hordofa (2009). Towards genetic classification of the Afan Oromo dialects (Unpublished PhD Dissertation). The University of Oslo: Sweden.

[13] Mekuria Bulcha (1994). The language policies of Ethiopian Regimes and the history of written Afan Oromo: 1844-1994. Journal of Oromo Studies, 1(2), 91-116.

[14] Mokonenn Hundie (2002). Lexical Standardization in Oromo. AAU, Master's Thesis (Unpublished).

[15] MOE (1994). Ethiopian educational and training policy. Addis Ababa: St. George Printing Press.

[16] Papapavou, A and Pavlos, P. (Eds). (2007). Sociolinguistics and pedagogical dimensions of dialect in education. Newcastle: Cambridge Scholars Publishing.

[17] Stegman, V.G. (2007). English_Borana word list. Duquesne University: Spiritan Collection Ltd.

[18] Tamene Bitima (2006). Wallo Oromo Dialect. Journal of Oromo Studies. 13, (1\&2), 147-163.

[19] Tilahun Gamta (1993). Qube Afan Oromo: Reasons for choosing the Latin script for developing an Oromo alphabet. Journal of Oromo Studies, 1(1), 36-41.

[20] Wiirtu Jildii-7(1995). Swedish word list. Finfinne: Oromiya Cultural and Tourism Bureau.

[21] Wolfram, et al. (1999). Dialects in schools and communities. Mahwah: Lawrence Erlbaum Associate Publishers. 